Production

ENGINEERING ARCHIVES
2016, Vol. 12, No. 3, pp 22-29

ISSN 2353-5156

ISSN 2353-7779 (print version)

(online version)

Article history: Received: 17.08.2016

Accepted: 17.09.2016

Online: 30.09.2016

Available online on: http://www.qpij.pl

Exist since $4^{\text {rd }}$ quarter 2013

\title{
Unbridgeable gap between evolution of blue- print codes and communication - paradigm changing in production
}

\author{
Márk Győri ${ }^{1}$, Péter Ficzere ${ }^{2}$, László Lovas ${ }^{3}$ \\ ${ }^{1} \mathrm{PhD}$ Student; MSc in Technical Manager Engineering; assistant Lecturer, Department of Vehicle Parts and Structures Analysis; Budapest \\ University of Technology and Economics; H-1111 Budapest, Sztoczek u. 2.; gyori@kge.bme.hu \\ ${ }^{2} \mathrm{PhD}$ in Mechanical Sciences; MSc in Mechanical Engineering; senior lecturer; Department of Vehicle Parts and Structures Analysis; Bu- \\ dapest University of Technology and Economics; H-1111 Budapest, Sztoczek u. 2.; ficzere@kge.bme.hu \\ ${ }^{3} \mathrm{PhD}$ in Mechanical Sciences; MSc in Mechanical Engineering; associate Professor; Department of Vehicle Parts and Structures Analysis; \\ Budapest University of Technology and Economics; H-1111 Budapest, Sztoczek u. 2.; lovas@kge.bme.hu
}

\begin{abstract}
The traditional 2D drawing (hand drawing) in engineering has a commonly known communication code. These communication codes (type of line, width of line or other marks) makes the engineering communication easier, faster and safer. In the last couple of decades new computer aided design and manufacturing methods have been developed. The communication has been changed. This article aims to investigate the gap between software development and rules of communication. Although software support has developed the communication codes and basics have not been significantly changed. 2D drawing code is not yet fully included in modern 3D CAD software. Automatic 2D drawing generation from 3D computer models results problems, for example in sections, cuts and break-outs. This paper shows the most common problems and makes recommendation through harmonisation of the communication codes.
\end{abstract}

Key words - blueprints, design, communication, engineering

\section{Introduction}

Description of complex shapes is very difficult. That is why technical drawings are generally accepted as a special language to describe shapes and sizes. The drawing creates a connection between the designer, the manufacturer and the operator. If the link is not cor- rect, the information cannot be passed, or can be passed incorrectly (STASIAK-BETLEJEWSKA, POTKÁNY, 2015). It is, therefore, necessary for the application of drafting standards to minimise the error in data transmission over the connection (Fig. 1). 


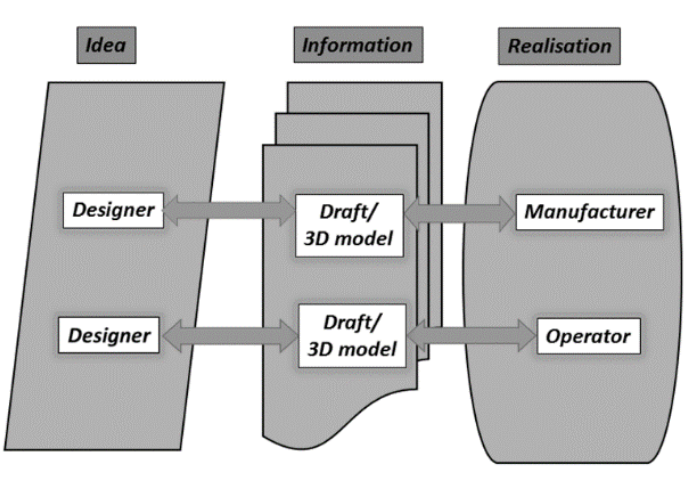

Fig. 1. Communiaction chain in Egnieering

Source: own study

As spoken and written language changes, the drawing standards also keep evolving in times. The first graphical representations can be found in the caveman era, in the form of cave paintings (Fig. 2).

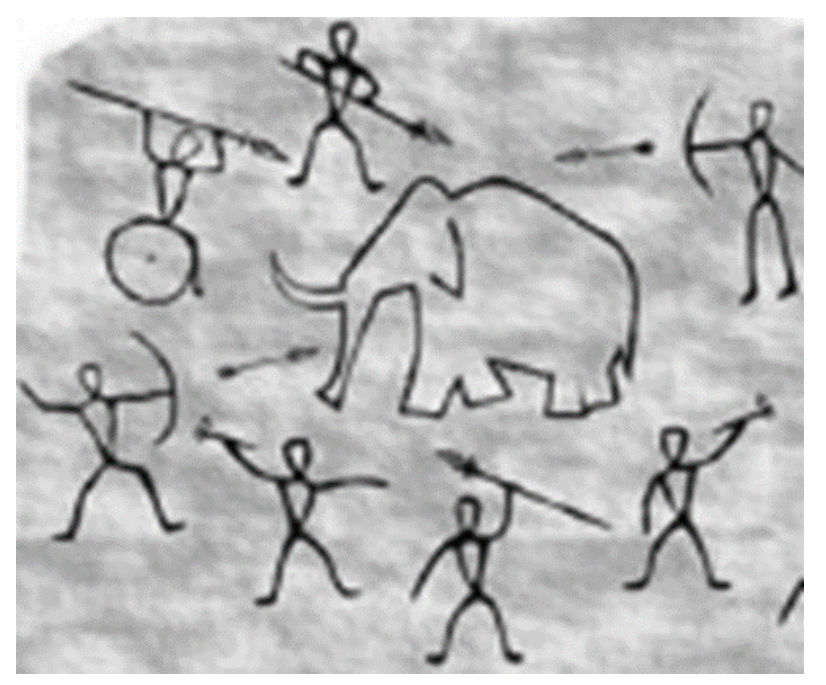

Fig 2. Cave drawings of prehistoric man

The cave drawings of prehistoric man also captured the images of a slice of reality. By using these drawings, previous experience was recorded and recalled; the animal was likely to be recognized which had to be faced while hunting. Therefore, it contributed to overcoming fear, and provided opportunity to prepare for the fight. The image, thus, became source of information. Of course, in this case it is only a twodimensional depicting, a visual display performance. A significant progress in the area of visual representation has been brought by Leonardo da Vinci (14521519). In his paintings, effort can be seen to show the objects and shapes in three dimensions and an excellent application of perspective depiction (Fig. 3). The shapes are shown clearly by perspective depiction, but there is no satisfactory information about the exact dimensions.

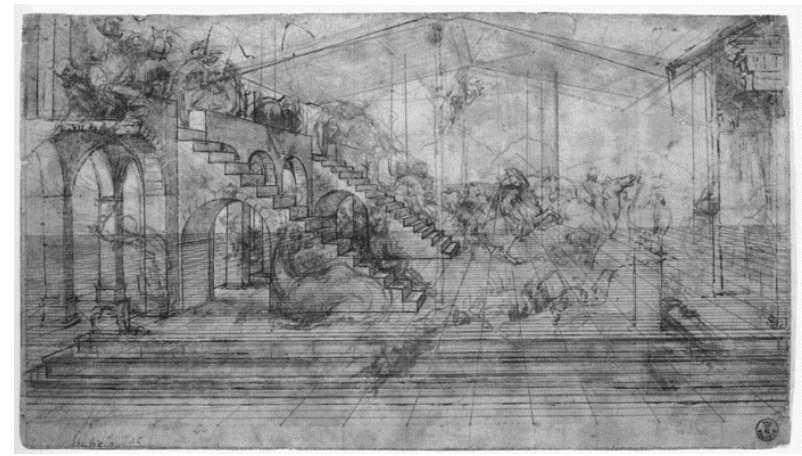

Fig. 3. The Adoration of the Magi (Leonardo)

During his whole life, Leonardo always attempted the most accurate representation possible. In his late works, he used different colours to show distances and depth sizes. For example, it is not ice able above the shoulder of Mona Lisa; the farther the part, the darker the blue colour. The section representation of technical drawings are also indebted to Leonardo (Fig. 4). What is more, he also used the modern sense of the word broken-up-sections and half-sections.

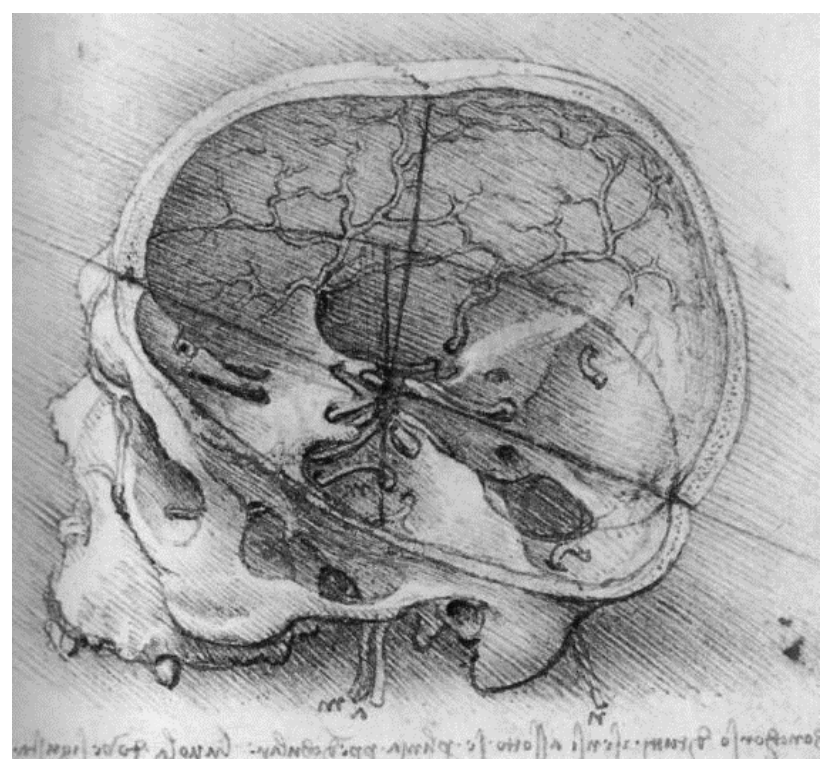

Fig. 4. Anatomical section (Leonardo) 
However, engineering applications are usually very complex structures; to represent them, Leonardo also had to choose the 3D geometry method (Fig. 5).

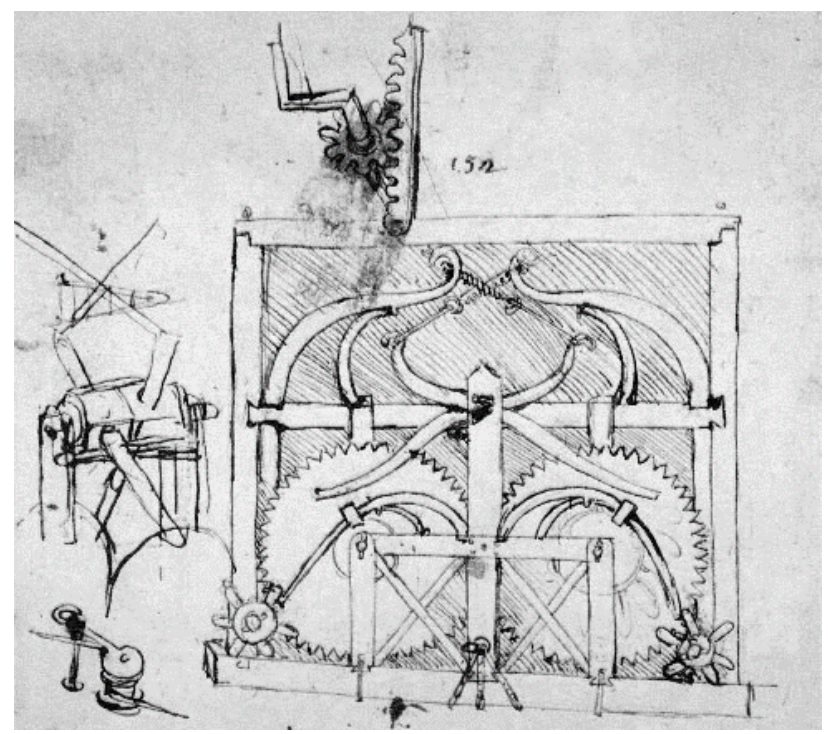

Fig. 5. Leonardo's self-propelled cart (Leonardo)

In Fig. 5. it can be observed that he tried to present the operation of the device where the mechanism and specific details can be also seen, for example gear linkage. Unfortunately, this plan could only be realized five hundred years later. The basics of the currently used code of mechanical representation evolved in the early twentieth century. The first monochrome copy procedures spread by this time and the rules were adapted to them. Instead of the previous use of various colours, line colours became only black. Different functions were signed by various types and thickness of lines. The views are basically plane projections, the rules of revealing internal details are created for handmade drawings. This regime was used in a significant part of the last hundred years.

In the last twenty years thanks to the modern 3D CAD-systems and the rapid spread of coloured printing and copying the system of rules seems to have become limited. (Lovas L., 2010) Nowadays, the planned parts are designed by the level of the freehand sketches. They are created as a 3D model in a CAD system immediately after the development of the main topology and function (COMPANY ET. AL., 2009). The whole development is done on computers, and there is no need for plane drawings for the production (CNC machines, 3D printing processes), (FICZERE, BORBÁs, 2016). The question arises: is there any need for using the conventional plane drawing rule systems? If yes, which parts of them are modern, and which parts are not worth applying anymore? A further advantage of $3 \mathrm{D}$ models against the $2 \mathrm{D}$ plane drawings is that they can be used for marketing purposes as well as interferences cheques, fit investigations, motion simulation (animation) and functional analysis can be made by them. Furthermore, it can also be used for surveying the loadability (numerical analysis), optimizing the geometry and material and for examination of the assembly possibility (IVANCO, KMET, FEDORKO, 2016, UleWicZ R., JELONEK D., MAZUR M. 2016, KRYNKE M. 2015, UlEWICZ R. 2013, NowAKOWSKA-GRUNT J., MAZUR M.).

First the main requirements of the drawing documentations will be investigated, after (it), the problems of plane drawings generated by CAD systems will be introduced. Finally, suggestions for modifying the drawing rules to the case of freehand drawings and CAD drawings will be given.

\section{General Requirements About Draw- ing Documentations}

The main rules about planning are clarity, simplicity and safety which means the followings in the area of technical drawings

- obvious documentations (drawing, parts list, technical description)

- simple understandability (readability)

- availability of all information (without redundancy)

- possibility of simple and quick representation in any circumstances

The components and structures must be creatable safely by the drawing, while the framed construction must be operable.

In the course of modelling the generated plane drawings can be part drafts or assembly drafts. The requirements of these two drawing documentation are partly the same and different.

The main requirement about part drafts is obviously the manufacturability. It means verifiability and the giving the necessary views, sections, symmetries, dimensions, surface roughness, form and orientation tolerances.

The requirements about assembly drafts are the followings: 
- clear definition of the relationships of joining components

- functions of related surfaces should be obviously traceable

- assembled status, position should be overview, question of decidability of assembly

- boundary conditions (positions, dimensions, stresses should be verifiable

By creating plane drawing the above given considerations must be observed as far as possible.

\section{Differences Between Plane Drawings And Generated Drafts}

If the component or mechanism has a 3D model, the simplest way of creating plane drawings is generating projections with the help of an embedded algorithm of the applied software. It happens usually with respect to the rules of drawings. With an exception to the rule if the component has such details or features which have rules of symbolic simplified representation are applied to in 2D drawings:

- thread,

- ribbing splinedshaft and hub,

- gears.

In case of threads, the representation is also simplified in three dimensions (Fig. 6), in order to spare with graphic memory and computational time, and the plane representation will also be simplified (MOLNAR, ET. AL., 2016, Sygut P., Klimecka-Tatar D., BORKOWSKI S.). In such cases colours are used to represent the features (for example the length of thread), but the solid geometry does not follow it.

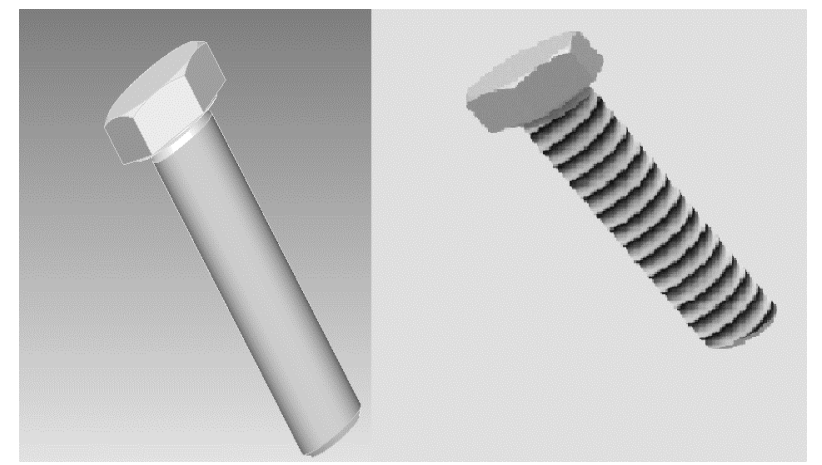

Fig. 6. Solid representation of a screw with simplified representation of the thread (colour and rendering)

Source: own study

Splines are not simplified in projections by software (Fig. 7).
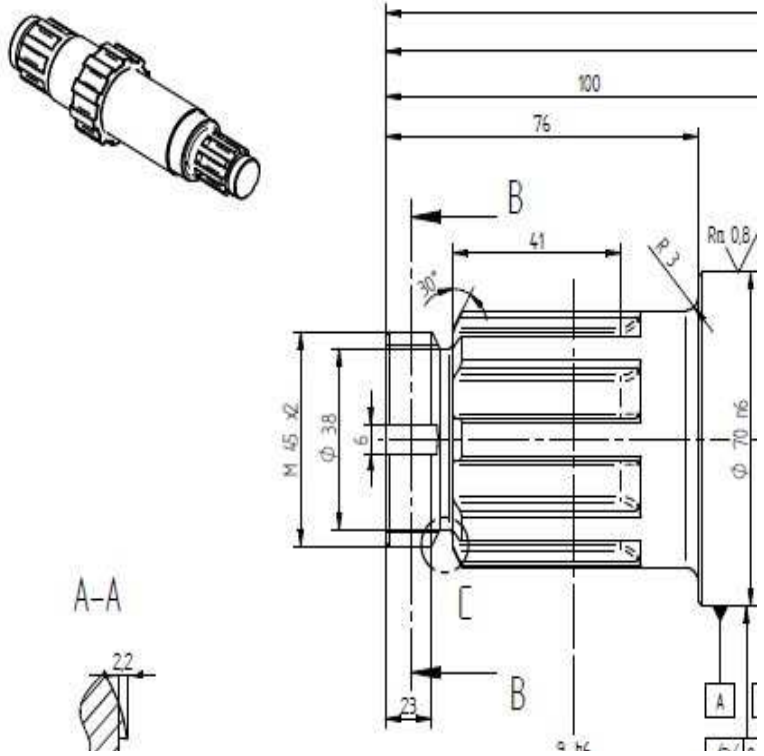

Fig. 7. Projected representation of spline shaft without simplification

Source: own study

At representing gearing also may not be simplified (Fig. 8), software aim to visualize the real shape and the generated representation is not only incorrect but makes reading the drawing more difficult, especially in case of joining gears.

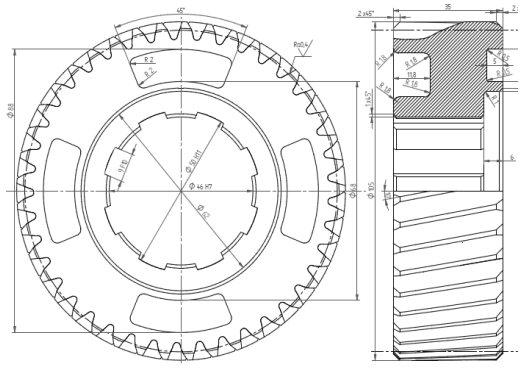

Fig. 8.: Drawing of a gear without simplification of splines and gear features

Source: own study

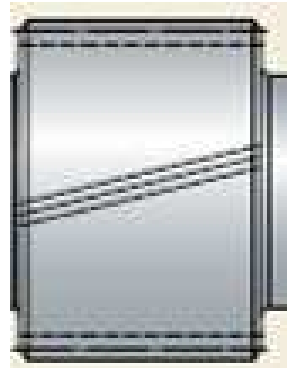

Fig. 9. Representation of gear with simplification

Source: own study
Another problem is the usage of different sections. Generating revolved sections which is a simple type of section, cannot be generated automatically. In case of broken-out-section the border line of the breakout also does not meet the current standard of engineering drawing (Fig. 10).

The reason of it is that modifying the default line types is quite difficult (it is possible only in groups at the same time). 
This problem has been solved in the latest versions of software, so the border-line of broken outs appears automatically in the correct form. Marking of tangential connections does also not meet the standards because rounding should be marked with only one tangent line, not two.

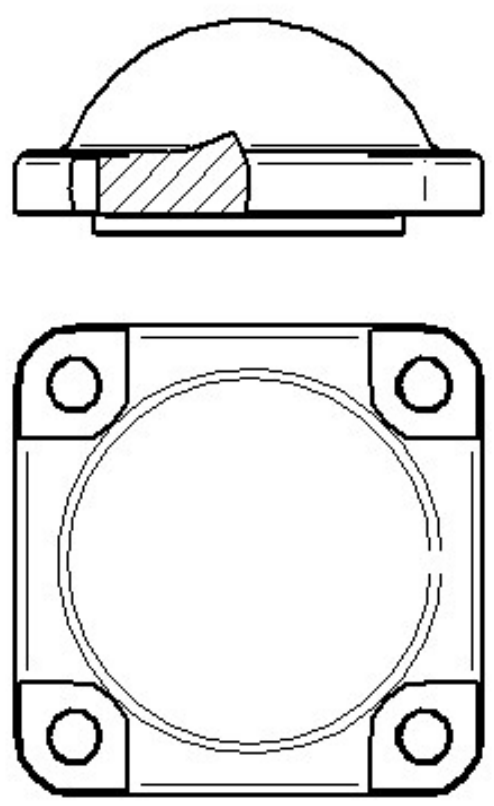

Fig. 10. Problem of border line of broken-out-section Source: own study

Rules of sections in the symmetry plane are also disregarded, software applies only full- or broken-out-sections.

It is clear that the necessary details can be represented fully, but in many cases it is much more difficult and needs more paper than a freehand drawing.

In general software does not apply the rulethat certain parts must not be sectioned lengthwise - mostly tight elements - to avoid mass effect such elements are for example shafts, pins, ribs, spokes (Fig. 11).

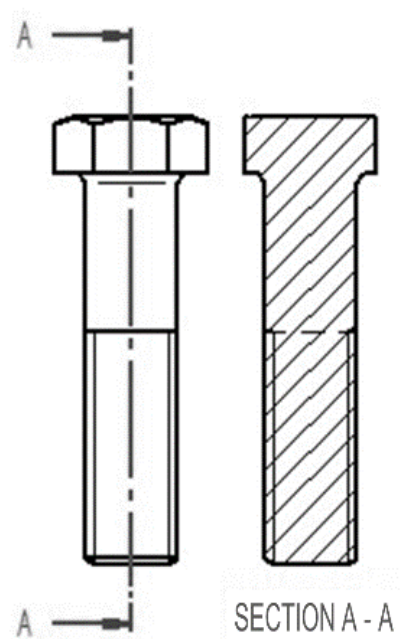

Fig. 11. Problem of section of tight, cylindrical part Source: own study

In case of rod-like or shaft-like-elements (hardware parts), such as pins, screws, shafts this feature can be defined which is taken into account by the CAD software.

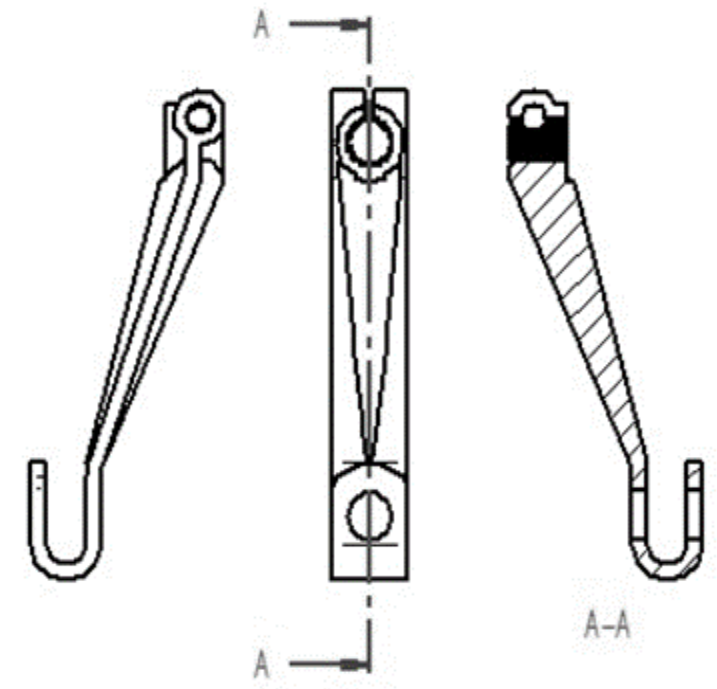

Fig. 12. Problem of sectioned representation of spline elements

Source: own study

Another problem is the section of gears. In case of straight or oblique tooth, the solid model is always sectioned by the cutting plane and the simplified representation is not applied. It is a frequent situation that in case of odd number of teeth on the one side the tooth surface can be seen but on the other side there is a sectioned tooth. In 
case of oblique teething it is more difficult to understand the drawing (Fig. 8).

In case of oblique projections it is difficult represent the symmetry lines and bolt hole circles. Mostly in software it is not adapted therefore symmetry lines follow the horizontal and vertical directions of the paper (Fig. 13).

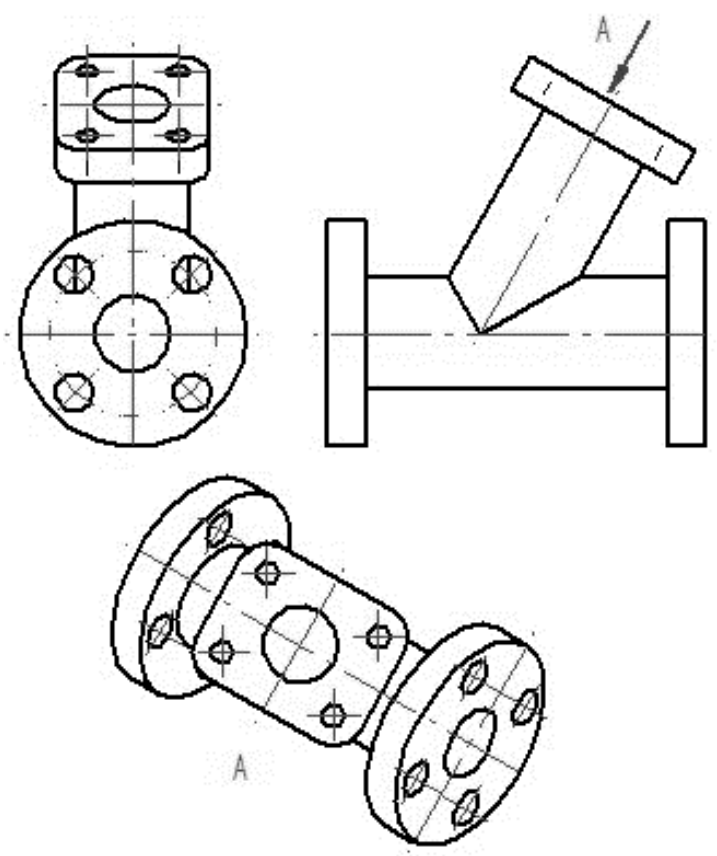

Fig. 13. Problem of representation of symmetry-lines and bolt hole circle

Source: own study.

If students study hand and software drawing simultaneously, they are inclined to accept to be correct without criticism, which they have seen on the screen.

\section{Harmonizing Of Hand And Software Drawing Habits, Suggested Modifica- tions}

In order to make the transition from the drawn 2D documentation to the generated 3D documentation does not pose any break neither for the designer, nor the user, if a bit late, but it would be appropriate to make recommendations to convert the machine drafting standards, as well as the developers of CAD systems.
Below - from our own experience - the following possibilities are emerging:

\subsection{Application of colours}

It is possible to use different colours for lines beside the thickness. It works at 2D software long ago. It was not very successful, because it is very different from the engineering way of thinking, and from the usual code system.

Instead of hatching of surfaces, or distinction of parts it could be possible to fill the surfaces with different colours inside the contours.

\subsection{Application of simplificatopns}

In case of threaded parts, splines and teething the simplified and realistic representation should be both accepted. At the figures of SKF threaded parts are represented in this way for decades (Fig. 14).

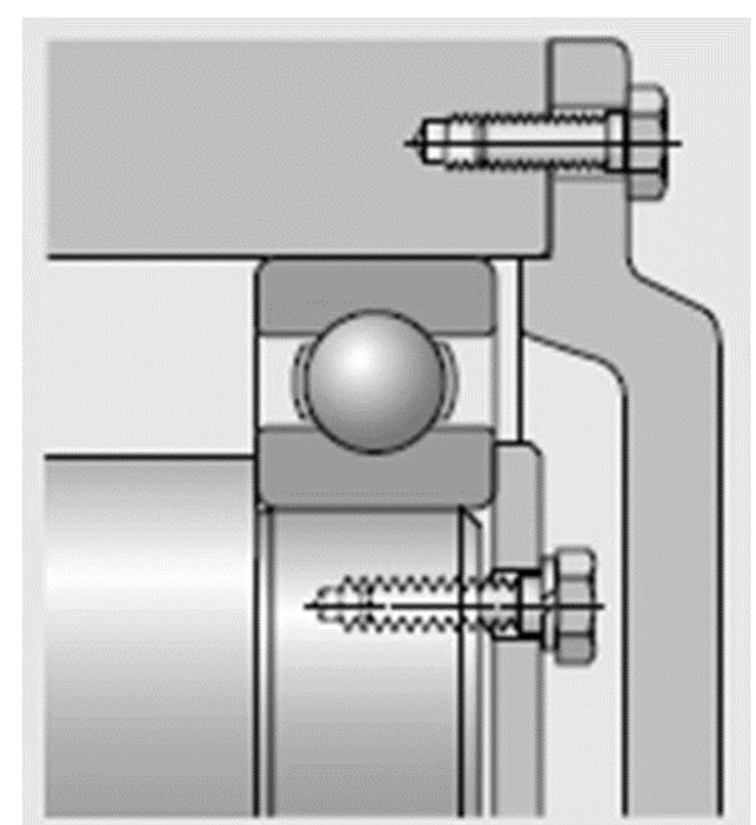

Fig. 14. Thread and threaded hole representation realistic $(S K F)$

Source: own study

Following this train of thought investigate the differences between the ways of representation of the clutch in the figure below. 


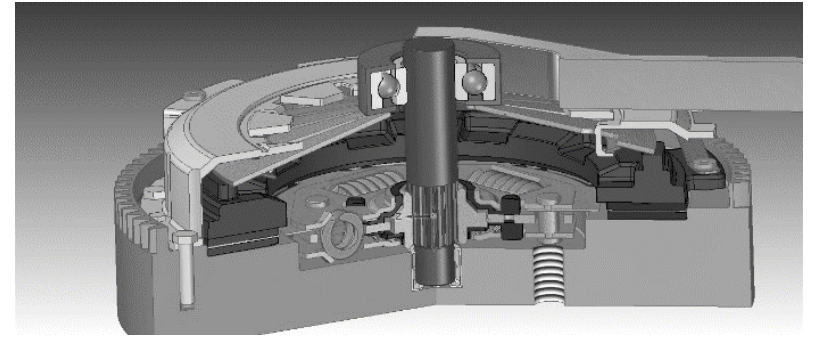

Fig. 15. Sectioned solid representation of clutch Source: own study

The figure is relatively well-arranged, but attention should be paid to the fact that axis type elements should not be sectioned. The next figure depicts the sectioned view of the same clutch made by the same cutting plane. It is important to notice that the software in not able to represent the splined shaft in a symbolic way, it also needs a great amount of post correction.

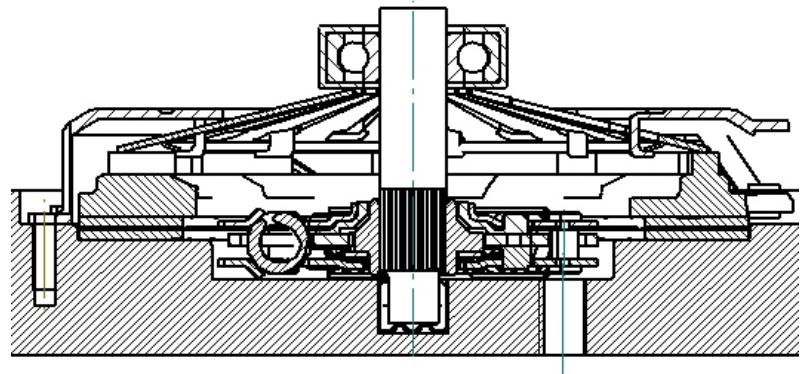

Fig. 16. Section view of assembled clutch Source: own study

Then examine the result of making solid section view using different colours instead of standard specifications / rules.

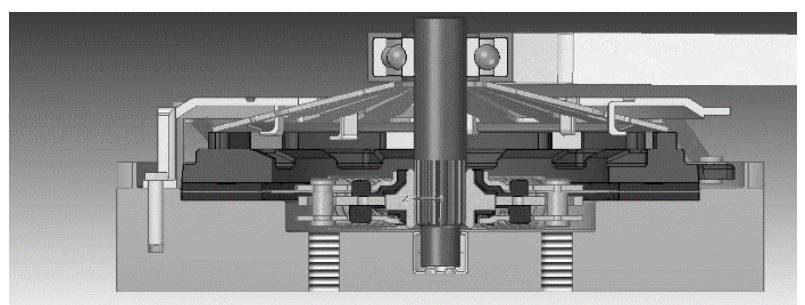

Fig. 17. Section of a clutch in solid environment Source: own study

It is also important to mention that in solid environment the software is not able to generate revolved section, also more sections are needed to represent each connections exactly.
It is visible that in case of symmetric element (for example bearings) it is specifically disturbing if that is not in the right position.

It is important to notice, although attention was paid to it, that the cutting plane should not cross the teeth of flywheel-ring gear, so that the teeth could be seen in view, not in section, but the teething is still difficult to interpret for computers.

\subsection{Use of axonometric figures}

With the use of solid CAD software views and sections are just generated, which can be prepared quite quickly.

It would be practical to prescribe to represent the solid view of the element as well on the draft, it could help in interpreting the drawing especially in case of complex, intricate elements.

\subsection{Suggested modifications for CAD software developers}

On the generated drafts from the realistic 3D visualization the representation should be simplified as far as possible (threads, gear teeth, etc.)

Some software (for example Solid Edge) already has the opportunity to use simplified representation, but these do not always meet the standard code of technical drawings.

The border lines of sections and broken-out sections should be defined and formatted simpler.

It is suggested to apply this rule in case of auxiliary sectioning, ribs and gears, so that the gear teething or rib could be seen in view, independently of the position of the plane section.

\section{Summary}

This paper attempted to reveal the main problems. It is suggested to harmonize the code system of the two different ways of creating drawings within the limits of common sense and using the modern technical opportunities.

It is important to remark that the regulations and recommendations of standards can be different in many cases. Software must meet not only European 
but also American and Japanese standards. It can be solved with different predefined profiles.

It should be always kept in mind that the purpose of drawings is communication. They establish the connection between people working in the planning, manufacturing, and operation phase of the product. That is why it should be strained after the most simple, clear and fast opportunities of representation.

CAD systems are not always and not everywhere available. What is more, in most cases, for example, in case of a malfunction of an element to receive its technical details its parameters and its installation environment only a monochrome pencil can be available.

Therefore, it is important to consider whether non-symbolic representation of threads, material patterns is applicable in all cases, or the conventional regulations such as hatching in different directions should be followed.

By the appearance of solid modelling systems the code system of technical drawings could be more permissive. In some cases more solutions could be permitted, but only with observing and conserving the original symbolic representation.

\section{Literature}

1. Company P., Contero M., Varley P. Aleixos N., NAYA F. Computer-aided sketching as tool to promote innovation int he new product development process. Computers in Industry, vol. 60, pp. 592-603, 2009.

2. FiCZERE, P., \&BorBÁs, L. New Application of 3D Printing Method for Photostress Investigation. Materials Today: Proceedings, 3(4), 969-972, 2016.

3. Ivanco, V., KMEt, S., \&Fedorko, G. Finite element simulation of creep of spiral strands. Engineering Structures, 117, 220-2382, 016.

4. LOVAS L. Technical Drawing I. [in Hungarian: Müszakiábrázolás I.] Lecture notes for BSc students, 2010, http://www.tankonyvtar.hu/hu/tartalom/ tamop412A/0018_Muszaki_abrazolas_1/adatok.html

5. Molnar, V., Fedorko, G., Stehlikova, B., MichaliK, P., \&KOPAS, M. Influence of tension and release in piped conveyor belt on change of normal contact forces in hexagonal idler housing for pipe conveyor loaded with material. Measurement, 84, 21-31, 2016.

6. Stasiak-Betlejewska, R., \& PotKány, M. Construction Costs Analysis and its Importance to the Economy. Procedia Economics and Finance, 34, 35-42, 2015 .
7. UlewiCZ R., JelONEK D., MAZUR M. Implementation of logic flow in planning and production control. Management and production engineering review. Vol. 7, issue 1, pp. 89-94, 2016.

8. KRYNKE M. The dynamic state monitoring of bearings system. Production Engineering Archives. Vol. 6 (1). pp. 35-38, 2015.

9. UlEwiCZ R. Ocena efektywności funkcjonowania Systemu Zapewnienia Jakości. Production Engineering Archives. Vol. 1(1) pp. 35-38, 2013.

10. SYguT P., KLIMECKA-TATAR D., BorkOwSKI S. Theoretical Analysis of the Influence of Longitudinal Stress Changes on Band Dimensions During Continuous Rolling Process, Archives of Metallurgy and Materials, Vol. 61. Iss. 1, pp .183-188, 2016.

11. Ingaldi M., DzIUBA Sz. T. Modernity Evaluation of the Machines Used During Production Process of Metal Products, METAL 2015. 24th International Conference on Metallurgy and Materials, Brno, Czech Republic, 2015.

12. NowaKowska-Grunt J., MaZUR M. Safety Management in Logistic Processes of Metallurgical Industry, METAL 2015. 24th International Conference on Metallurgy and Materials, Brno, Czech Republic, 2015. 